\title{
Efficacy and safety of intravenous chemotherapy during intensive treatment phase in patients with newly diagnosed pulmonary tuberculosis
}

The authors declare no financial disclosure

\begin{abstract}
Introduction: The purpose of our study was to examine the efficacy and safety of intravenous chemotherapy during intensive treatment phase in patients with newly diagnosed pulmonary tuberculosis (pulmonary TB).

Material and methods: The study involved 92 patients with newly diagnosed pulmonary TB aged between 20 and 68 . All patients with newly diagnosed pulmonary TB and chemosensitive tuberculosis were enrolled in the study. The patients were allocated to two groups. The first (control) group of 46 patients received standard chemotherapy orally. The second (main) group consisted of 46 patients who were prescribed isoniazid, rifampin, ethambutol by i.v. infusion, and pyrazinamide orally as a part of the standard treatment.

Results: Symptoms of intoxication and chest manifestations in pulmonary TB patients from the second group were eliminated faster than the same symptoms in the group 1. In the group 2, the mycobacterial clearance in sputum smears was achieved more rapidly, and up to 2 months it was reached in 37 patients $(80.43 \%)$, while in the control group in 25 patients $(54.35 \%), p=0.0066$. Destruction healing and inflitrative change alleviation after 4 months was reached in 38 patients (82.61\%) (in control group - 28 (60.87\%), $(p=0.0192)$. No additional negative effects were detected when compared with the control group at any time.

Conclusions: Thanks to i.v. chemotherapy, clinical manifestations of the in-patients with pulmonary TB were eliminated faster, severe side effects of anti-TB drugs were not noticed, time of bacterial clearance and healing of destruction was shorter, healing frequency of destructions increased and the of residual changes decreased.
\end{abstract}

Key words: tuberculosis, treatment of tuberculosis, intravenous treatment of tuberculosis, antituberculous drugs

Adv Respir Med. 2018; 86: 159-167

\section{Introduction}

Tuberculosis (TB) continues to hold a dominant position among frequent infections, constituting a threat to the population of most countries, including the economically developed ones [1]. TB problem is extremely important in Ukraine, where since 1995 it has been registered an epidemic, and although the growth rate of morbidity and mortality from TB has been stabilized in recent years, the situation still remains difficult.
Despite the reduction in the growth of total incidence rate, prevalence and mortality from TB for the last 5 years remain high and exceed 2-3 times the epidemic threshold [1,2].

The most prominent achievements of phthisiology are associated with the development of antimycobacterial therapy. Performance targets for further improvement of the newly diagnosed pulmonary TB treatment determine not only the increasing of destructions closure frequency and negation of sputum, but also the use of therapies

Address for correspondence: Dmytro Butov, Kharkiv National Medical University, 4 Nauky Avenue, 61022 Kharkiv, Ukraina, e-mail: dddimad@gmail.com DOI: 10.5603/ARM.a2018.0024

Received: 13.03.2018

Copyright (C) 2018 PTChP

ISSN 2451-4934 
that can achieve sustainable results within shorter time without forming large residual changes in the lungs [3-5].

Modern methods of controlled therapy represent programmable treatment [6]. Foreign and domestic experience of DOTS program implementation has shown that treatment standardization and control procedures of its effectiveness are not always justified [7, 8]. The success of the used therapy depends with great frequency on the possibility to apply a full course of chemotherapy, namely the administration of the required number of drugs in adequate doses for the necessary duration of treatment [9, 10].

However, there remains a certain percentage of patients for whom this method of treatment does not lead to significant improvement of health. This generalized treatment method does not consider the presence of comorbidities and development of side effects of therapy, which require treatment correction [11]. Despite the high level of scientific and practical justification of existing standards of TB chemotherapy, its further improvement is necessary $[12,13]$.

The lack of therapeutic effect may be caused by the development of drug resistance [14], the inability to create optimal concentrations of the drugs in the blood and tissues [15] as a result of their incomplete absorption in the gastrointestinal tract [16] and accumulation in the inflammation area [4, 17], or rapid inactivation of the drugs [18].

In the course of clinical and experimental studies it was found that the therapeutic effect of ATD (anti- TB drugs) is directly related to the concentration of a drug in the blood, and therefore to the area of specific inflammation [19, 20]. According to the literature, there are some data about the use of intravenous (i.v.) chemotherapy in patients with TB meningitis. Those figures show that this type of intensive treatment reduces mortality of patients with TB meningitis [21]. In addition, effectiveness of i.v. chemotherapy for patients with TB and deficit of absorption have been also shown [22].

All this determines the search for ways to improve the treatment of patients with newly diagnosed pulmonary TB by optimization of the intensive phase of TB chemotherapy with i.v. use of ATD.

Thus, the purpose of our research was to study the effectiveness and safety of intravenous chemotherapy in the intensive phase of treatment of patients with newly diagnosed pulmonary TB (pulmonary TB).

\section{Material and methods}

\section{Patients}

This prospective, randomized, comparative study was conducted in SO "National Institute of phthisiology and pulmonology named after F. G. Yanovskyi NAMS of Ukraine”, Kyiv and Kharkiv National Medical University, Kharkiv, Ukraine.

The study involved 92 patients with pulmonary TB aged between 20 and 68 . The period of inclusion of patients in the study was from 2011 to 2017. All patients with pulmonary TB and chemosensitive TB were enrolled in the study. Patients were randomly allocated by computergenerated sequence into two groups. The first (control) group of 46 subjects received standard chemotherapy orally. The second (main) group consisted of 46 patients who were prescribed isoniazid, rifampin, ethambutol in standard dose by i.v. infusion, as a part of the standard treatment.

The randomization resulted in equal distribution of baseline characteristics: age, gender, height, body weight, comorbidities, serum biochemistry parameters, severity and various manifestations of the disease (Tables 1-3).

Active pulmonary TB was defined by a medical history and clinical findings compatible with TB, a chest X-ray showing lung involvement, and a positive sputum smear for acid-fast bacilli and positive culture for MTB. On the patients' admission to hospital, infiltrative pulmonary TB was the most common type and was observed in every patient from the first group. In the second group, infiltrative pulmonary TB was observed in 43 (93.48\%) patients. Moreover, 3 (6.52\%) individuals from the second group were diagnosed with disseminated pulmonary TB. Quantitative characteristics of TB cases within both groups of patients were evaluated and shown to be insignificant $(\mathrm{p}>0.05)$. The difference between the spread of the TB process in the lungs and the number and size of destructions was insignificant ( $p>0.05)$.

\section{Treatment regimen}

All patients from the first group received standard chemotherapy, consisting of orally administered isoniazid (0.3 g), rifampin (0.6 g), pyrazinamide (2 g), ethambutol (1.2 g) with a dose reduction after the intensive phase of the therapy. The ATD were procured through the Ukraine's centralized national supply system.

The second group was treated with i.v. chemotherapy, i.e. isoniazid (used in a dose of 100 $\mathrm{mg} / \mathrm{ml}$ in $5 \mathrm{ml}$ of i.v. (intravenous jet, slowly) - by stream infusion once per day for 60 days starting 
on admission to the hospital), rifampin (used in a dose of $600 \mathrm{mg}$ in $20 \mathrm{ml}$ of $0.9 \%$ in $200 \mathrm{ml}$ sodium chloride solution i.v. (intravenous drips, slowly) - by drop infusion once per day for 60 days starting on admission to the hospital), ethambutol (used in a dose of $100 \mathrm{mg} / \mathrm{ml}$ in $20 \mathrm{ml}$ of $5 \%$ in $200 \mathrm{ml}$ glucose solution i.v. (intravenous drips, slowly) - by drop infusion once per day for 60 days starting on admission to the hospital) and pyrazinamide ( $2 \mathrm{~g}$ in tablets orally). Intravenous administration of the ATD was performed in the ulnar vein. Parenteral chemotherapy was performed in the $2^{\text {nd }}$ group only during the intensive phase of treatment (60 doses), and during the continuation phase ATD were taken orally in a standard dosage.

\section{Laboratory evaluation}

A standard microbiological examination of a stained sputum smear using the Ziehl-Neelsen and culture Lowenstein-Jensen methods was conducted prior to study entry and on the $30^{\text {th }}, 60^{\text {th }}$, $90^{\text {th }}$, and $150^{\text {th }}$ day from the start of the treatment. Isolates of MTB were tested for sensitivity to first- and second-line anti-TB drugs with a commercially available kit (Tulip Diagnostics Pvt Ltd., Goa, India). The biochemical parameters were evaluated using standard routine techniques at baseline and repeated 2 months later.

Bacteriostatic blood activity (BBA) was identified in TB patients against the standard laboratory strain of the Mycobacterium tuberculosis (MBT) H37Rv on the liquid Proskauer-Beck medium using the procedure of Rudoy VV [23]. The elements of test-strain film were placed into test-tube and incubated in the thermostat during 10 days. At the presence of growth in the control sample, which covered its entire surface, the results were counted. The level of BBA was estimated according to the greatest blood dilution, where the MBT growth inhibition was observed. The BBA level was considered low in dilutions of 1: 2-1:4; average 1: 8-1:16; high 1:32-1:512.

All patients admitted to the hospital were tested for HIV with the use of rapid tests. All subjects were HIV-negative.

\section{X-ray evaluation}

Pathological peculiarities, for example, the severity of the disease and changes in localization, were assessed through X-ray. Chest fluorography was performed in the outpatient department for every subject involved in the study. In cases of pathological findings, we conducted a chest X-ray (two views). Targeted tomography of the destructed area on selected sections was performed in every patient. Interpretation of the thorough X-ray examination allowed us to estimate the first TB diagnosis, specifically, to detect localization, severity, and peculiarities of TB destructions in the lungs.

X-ray monitoring of patients was repeated every 2 months following the start of treatment until the end of the continuation phase (6 months).

\section{Statistical evaluation}

The obtained data were statistically analyzed using standard Student $t$ test [24]. The difference was considered to be significant at $\mathrm{p}<0.05$.

\section{Ethics approval and consent to participate}

The project was approved by the Ethics Committee of the SO "National Institute of phthisiology and pulmonology named after F. G. Yanovskyi NAMS of Ukraine", Kyiv, Ukraine. It was conducted according to the Declaration of Helsinki standards. All of the patients gave written informed consent and explicitly provided permission for treatment and blood analyses, as well as for the collection of relevant clinical data.

\section{Results}

This study comprised 92 TB patients. The baseline characteristics of patients in the two treatment groups were not statistically different, indicating that the outcome was not biased by sample heterogeneity (Tables 1-3).

Regression of intoxication and chest symptoms were the hallmarks of estimating how rapidly disease manifestation terminates after i.v. chemotherapy administration. Chest symptoms were evaluated through dyspnea, cough, and chest pain reduction or alleviation. Intoxication symptom regression was evaluated regarding subjective symptoms (increased appetite, general revival, fatigue, and sweating alleviation), normalization of body temperature, and body weight, which were considered symptoms of TB intoxication. Data are shown in Table 2. Therefore, in the second group, patients demonstrated more rapid intoxication and chest symptom alleviation than in the first group. Fever is mainly related to the severity of the specific process in the lungs lesions. They attenuated more rapidly in patients of the second group in comparison with the first group, which is explained by the high detoxication effect of i.v. chemotherapy during the treatment. This can be accounted for a low number of side effects of the therapy among the 
Table 1. Baseline characteristics of patients with pulmonary TB

\begin{tabular}{lccc}
\hline Characteristics & $\begin{array}{c}\text { Group 1 } \\
\mathbf{n}=\mathbf{4 6}\end{array}$ & $\begin{array}{c}\text { Group 2 } \\
\mathbf{n = 4 6}\end{array}$ & p-value \\
\hline Age & $42.06 \pm 1.20$ & $40.78 \pm 1.24$ & 0.4621 \\
Males & $36(78.26 \%)$ & $32(69.57 \%)$ & 0.3425 \\
Females & $10(21.74 \%)$ & $14(30.43 \%)$ & 0.3425 \\
Height, cm & $166.2 \pm 1.55$ & $162.9 \pm 1.52$ & 0.1371 \\
Weight, kg & $55.09 \pm 1.29$ & $55.78 \pm 0.99$ & 0.6710 \\
Co-morbidities*: & & & 0.6355 \\
Diseases of the respiratory system & $13(28.26 \%)$ & $11(23.91 \%)$ & 0.6745 \\
Diseases of the cardiovascular system & $19(41.30 \%)$ & $21(45.65 \%)$ & 0.5829 \\
Diseases of the gastrointestinal tract & $7(15.22 \%)$ & $9(19.57 \%)$ & 0.3353 \\
Diseases of the central nervous system & $4(8.70 \%)$ & $7(15.22 \%)$ & 0.6469 \\
Disease of the urogenital system & $2(4.35 \%)$ & $3(6.52 \%)$ & 1.000 \\
Rheumatic diseases & $2(4.35 \%)$ & $2(4.35 \%)$ & 0.5829 \\
Diabetes & $7(15.22 \%)$ & $9(19.57 \%)$ & 0.5570 \\
Psoriasis & $2(4.35 \%)$ & $1(2.17 \%)$ & $9(19.57 \%)$ \\
Chronic alcoholism & $8(17.39 \%)$ & & 0.7882 \\
\hline
\end{tabular}

*in many patients, concomitant diseases were combined

Table 2. Period of reduction of tuberculosis clinical signs in patients of the groups

\begin{tabular}{|c|c|c|c|c|c|c|c|c|}
\hline \multirow[t]{3}{*}{ Clinical symptoms } & \multicolumn{3}{|c|}{ Group 1} & \multicolumn{5}{|c|}{ Group 2} \\
\hline & \multicolumn{2}{|c|}{$\begin{array}{l}\text { No. at the } \\
\text { beginning of } \\
\text { treatment }\end{array}$} & \multirow{2}{*}{$\begin{array}{c}\text { Terms of } \\
\text { disappearance } \\
\text { of clinical signs } \\
\text { (months) }\end{array}$} & \multicolumn{2}{|c|}{$\begin{array}{l}\text { No. at the } \\
\text { beginning } \\
\text { of treatment }\end{array}$} & \multirow[t]{2}{*}{ p-value\# } & \multirow{2}{*}{$\begin{array}{c}\text { Terms of } \\
\text { disappearance } \\
\text { of clinical signs } \\
\text { (months) }\end{array}$} & \multirow[t]{2}{*}{ p-value* } \\
\hline & $\mathrm{n}$ & $\%$ & & $n$ & $\%$ & & & \\
\hline \multicolumn{9}{|l|}{ Intoxication symptoms: } \\
\hline Weakness & 28 & 60.87 & $2.77 \pm 0.59$ & 33 & 71.74 & 0.2700 & $1.22 \pm 0.36$ & 0.0238 \\
\hline Loss of appetite & 10 & 21.74 & $2.49 \pm 0.75$ & 13 & 28.26 & 0.4708 & $0.87 \pm 0.21$ & 0.0298 \\
\hline Fatigue & 13 & 28.26 & $3.67 \pm 0.39$ & 15 & 32.61 & 0.6508 & $2.06 \pm 0.41$ & 0.0088 \\
\hline Night sweats & 22 & 47.83 & $3.41 \pm 0.69$ & 25 & 54.35 & 0.5323 & $1.08 \pm 0.48$ & 0.0070 \\
\hline Increased body temperature & 26 & 56.52 & $2.68 \pm 1,01$ & 30 & 65.22 & 0.3929 & $0.61 \pm 0.39$ & 0.0490 \\
\hline $\begin{array}{l}\text { Chest symptoms: } \\
\text { Cough }\end{array}$ & 36 & 78.26 & $4.89 \pm 0.71$ & 38 & 82.61 & 0.5987 & $2.14 \pm 0.77$ & 0.0107 \\
\hline Dyspnea & 24 & 52.17 & $1.89 \pm 0.53$ & 27 & 58.70 & 0.5294 & $0.51 \pm 0.30$ & 0.0235 \\
\hline Pain in the chest & 4 & 8.70 & $3.57 \pm 0.49$ & 5 & 13.04 & 0.5043 & $1.38 \pm 0.51$ & 0.0189 \\
\hline
\end{tabular}

${ }^{*}$ the $p$-value is the significance of difference between parameters in Groups 1 and 2 (No. at the beginning of treatment); \# the p-value is not the significance of difference between parameters in Groups 1 and 2 (Terms of disappearance of clinical signs)

observed patients of the $2^{\text {nd }}$ group, which is associated with the slow administration of rifampin and ethambutol in a reasonably large amount of solution $(400 \mathrm{ml})$ per day.

When studying the basic biochemical indicators during the treatment (Table 3), we did not find significant changes in the concentration of total bilirubin and protein - these indicators were within normal range either before the treatment or after two months except for the rare cases. However, special attention should be paid to indicators such as alanine aminotransferase (ALT) and aspartate aminotransferase (AST) concentrations. As shown in Table 3, the TB toxicity in the organisms of patients of the group 2 prior to treatment was higher compared to the 1st group. After 


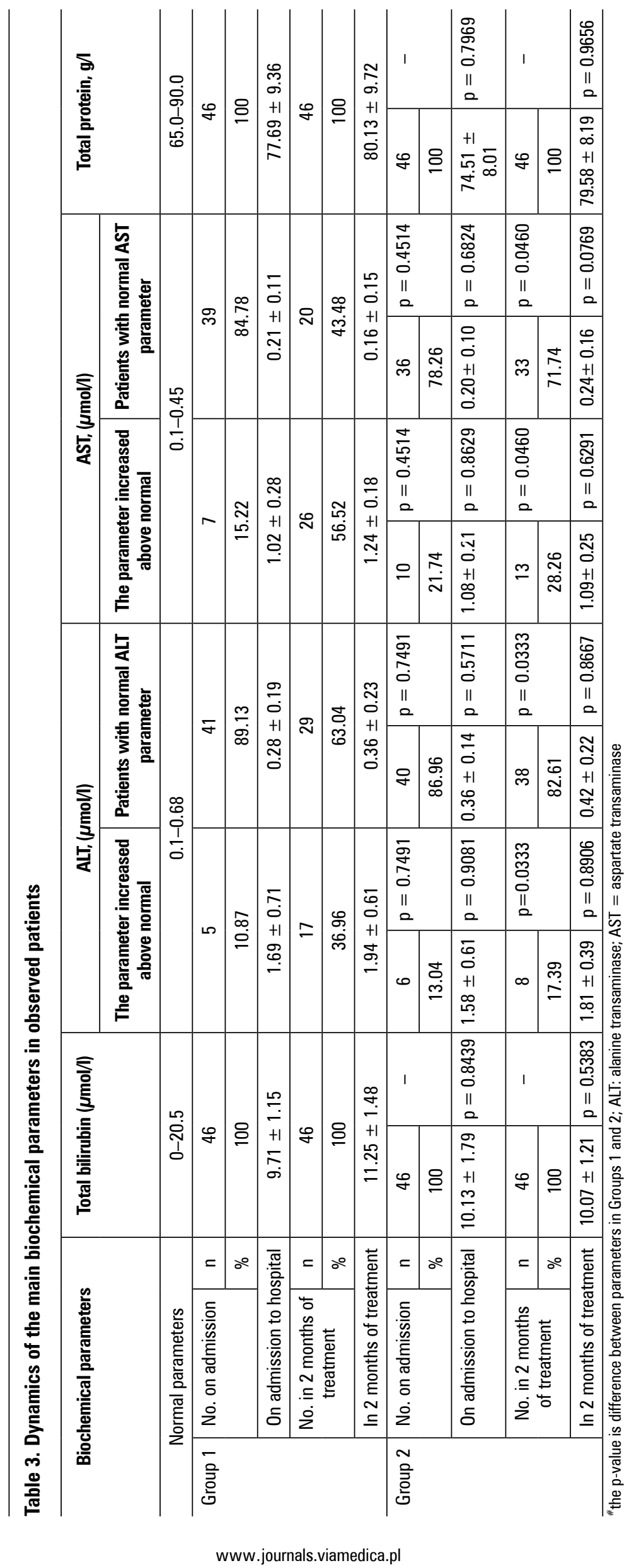




\section{Table 4. Bacteriostatic blood activity relative to the strain H37Rv}

\begin{tabular}{|c|c|c|c|c|c|c|c|c|c|c|c|c|c|}
\hline \multirow{3}{*}{$\begin{array}{c}\text { Hour } \\
\text { of } \\
\text { study }\end{array}$} & \multirow{3}{*}{$\begin{array}{c}\text { Groups of } \\
\text { patients }\end{array}$} & \multicolumn{12}{|c|}{ The values of bacteriostatic activity of blood } \\
\hline & & \multicolumn{3}{|c|}{$\begin{array}{c}\text { Small } \\
1: 2-1: 4\end{array}$} & \multicolumn{3}{|c|}{$\begin{array}{l}\text { Medium } \\
1: 8-1: 16\end{array}$} & \multicolumn{3}{|c|}{$\begin{array}{c}\text { High } \\
1: 32-1: 512 \\
\end{array}$} & \multicolumn{3}{|c|}{$\begin{array}{c}\text { Medium and high } \\
1: 8-1: 512\end{array}$} \\
\hline & & $\mathbf{n}$ & $\%$ & & $\mathbf{n}$ & $\%$ & & $\mathbf{n}$ & $\%$ & & $\mathbf{n}$ & $\%$ & \\
\hline \multirow[t]{2}{*}{1} & $\begin{array}{l}1 \text { group } \\
\mathrm{n}=46\end{array}$ & - & - & - & 31 & 67.39 & $\mathrm{p}<0.0001$ & 15 & 32.61 & $\mathrm{p}<0.0001$ & 46 & 100 & - \\
\hline & $\begin{array}{l}2 \text { group } \\
n=46\end{array}$ & - & - & & 6 & 13.04 & & 40 & 86.96 & & 46 & 100 & \\
\hline \multirow[t]{2}{*}{3} & $\begin{array}{l}1 \text { group } \\
n=46\end{array}$ & - & - & - & 23 & 50.00 & $p=0.2064$ & 23 & 50.00 & $p=0.2064$ & 46 & 100 & - \\
\hline & $\begin{array}{l}2 \text { group } \\
n=46\end{array}$ & - & - & & 17 & 36.96 & & 29 & 63.04 & & 46 & 100 & \\
\hline \multirow[t]{2}{*}{6} & $\begin{array}{c}1 \text { group } \\
n=46 \\
(6)\end{array}$ & 18 & 39.13 & $p=0.5152$ & 28 & 60.87 & $\mathrm{p}<0.0001$ & - & - & - & 28 & 60.87 & $p=0.5152$ \\
\hline & $\begin{array}{c}2 \text { group } \\
\mathrm{n}=46 \\
(8)\end{array}$ & 15 & 32.61 & & 7 & 10.87 & & 24 & 52.17 & & 31 & 67.39 & \\
\hline
\end{tabular}

"The difference between indicators 1 and 2 groups

two months of treatment concentration of these indicators in patients of the group 1 increased significantly due to complications related to the ATD in the liver and heart. An opposite trend was noticed in patients from the group 2, which was associated with i.v. administration of ATD, both for TB and drug intoxication.

We have made researches of the drugs pharmacokinetics depending on method of their application. The choice of the examination timing was based on the pharmacodynamic properties of preparations and character of the MBT growth, the need to create high peak concentrations in the blood and hence the corresponding values of the BBA for successful treatment of TB patients.

Thus, in the $1^{\text {st }}$ hour of the research, average and high BBA values in 100\% of the cases among the groups were determined. In the $2^{\text {nd }}$ group, the high BBA values in the $1^{\text {st }}$ hour of the research were significantly higher in comparison with the control group ( $\mathrm{p}<0.05)$.

In the $3^{\text {rd }}$ hour after the application of drugs, the BBA level was recalculated. It should be noted that although the consolidated figures for the mean and high values of BBA in the $1^{\text {st }}$ and $2^{\text {nd }}$ groups were observed in $100 \%$ of cases, the number of patients with high BBA level prevailed in the $2^{\text {nd }}$ group, where intravenous administration of drugs was applied.

In the $6^{\text {th }}$ hour of the research, the data of the $1^{\text {st }}$ and $2^{\text {nd }}$ groups were characterized by a further decrease of the bacteriostatic blood activity and its detection at low levels. In the group where patients received oral chemotherapy, the high BBA levels were not detected in any case. Intravenous use of ATD was slightly lower taking into consideration the consolidated figures of mean and high BBA levels compared to the group where ATD was taken orally, but this group was characterized by determination of high BBA levels in contrast to the first group where high BBAs were not detected (Table 4).

One of the most important criterion for characterizing the treatment efficacy of patients with pulmonary TB is the frequency of abacillation in patients (Tables 5, 6). According to the presented data, the frequency of observed abacillation using both microscopic and culture methods was significantly more real in the group 2 than in the $1^{\text {st }}$ one.

In addition, another important criterion characterizing the treatment effectiveness of patients with pulmonary TB is healing of the destructions and disappearance of infiltrative changes (Table 7). Throughout the period of observation, the healing of destructions of lung tissue was recorded more often among the patients from the second group than in the first one.

Regarding the terms of disappearance of infiltrative changes (Table 7), so far all the observed groups were consistent with the terms of destructions healing. The only exceptions are the rare cases where infiltration had disappeared before the destruction healing occurred, or vice versa, 
Table 5. Indicators of acid-fast bacilli excretion cessation as evidenced by microscopic examination of sputum and bronchial washing

\begin{tabular}{|c|c|c|c|c|c|}
\hline \multirow[t]{2}{*}{ Stages of treatment (months) } & \multicolumn{2}{|c|}{ Group 1} & \multicolumn{2}{|c|}{ Group 2} & \multirow[t]{2}{*}{ p-value } \\
\hline & $\mathbf{n}$ & $\%$ & $\mathbf{n}$ & $\%$ & \\
\hline On admission to hospital & 39 & 84.78 & 41 & 89.13 & 0.5365 \\
\hline 1 & 18 & 46.15 & 29 & $70.73^{*}$ & 0.0238 \\
\hline 2 & 12 & 30.77 & 10 & 24.39 & 0.5238 \\
\hline 3 & 5 & 12.82 & 2 & 4.88 & 0.2078 \\
\hline 5 & 4 & 10.26 & 0 & 0 & - \\
\hline
\end{tabular}

* the p-value is difference between parameters in Groups 1 and 2

Table 6. Indicators of acid-fast bacilli excretion cessation as evidenced by bacteriologic examination of sputum and bronchial washing

\begin{tabular}{|c|c|c|c|c|c|}
\hline \multirow[t]{2}{*}{ Stages of treatment (months)* } & \multicolumn{2}{|c|}{ Group 1} & \multicolumn{2}{|c|}{ Group 2} & \multirow[t]{2}{*}{ p-value } \\
\hline & $\mathbf{n}$ & $\%$ & $\mathbf{n}$ & $\%$ & \\
\hline 2 & 25 & 54.35 & 37 & $80.43^{*}$ & 0.0066 \\
\hline 5 & 19 & 41.30 & 8 & $17.39^{*}$ & 0.0106 \\
\hline
\end{tabular}

Table 7. Indicators of destruction lesion healing and infiltrative change alleviation in pulmonary tissue.

\begin{tabular}{|c|c|c|c|c|c|}
\hline \multirow[t]{2}{*}{ Stages of treatment (months) ${ }^{*}$} & \multicolumn{2}{|c|}{ Group 1} & \multicolumn{2}{|c|}{ Group 2} & \multirow[t]{2}{*}{ p-value } \\
\hline & $\mathbf{n}$ & $\%$ & $\mathbf{n}$ & $\%$ & \\
\hline 2 & 18 & 39.13 & 29 & $63.04^{*}$ & 0.0204 \\
\hline 4 & 28 & 60.87 & 38 & $82.61^{*}$ & 0.0192 \\
\hline Total to 6 & 36 & 78.26 & 41 & 89.13 & 0.1570 \\
\hline
\end{tabular}

a Index value at each stage is calculated based on previous values

* the $p$ value is difference between parameters in Groups 1 and 2

when infiltration of the lung continued for some time at a time of healing.

Thus, the healing timeframes of destructions of patients from the group 2 were significantly shorter than those from the group 1. This may be related to a more massive concentration of i.v. chemotherapy at the beginning of treatment followed by penetration of ATD into the abnormal focus earlier than at oral application.

The immediate effectiveness of treatment would be covered incompletely, if the nature of residual changes after completion of the main course of antimycobacterial therapy in both groups was not assessed.

When using i.v. chemotherapy in patients with pulmonary $\mathrm{TB}$, there are less residual changes observed: small residual changes at the cavern site which were healed, or absence of even minimal radiological changes stated in $29(63.04 \%)$ patients versus $18(39.13 \%)$ in the group $1(\mathrm{p}=$ 0.0158 ), and large residual changes accordingly in $17(36.96 \%)$ and $28(60.87 \%)(p=0.0204)$.

\section{Discussion}

TB is out of control in developing countries due to increasing poverty, drug-resistant TB and HIV coinfection [1,2]. The use of tablet forms of ATD does not always ensure the patient's recovery. This may have many causes, such as comorbidities, the presence of malabsorption syndrome and others, which translates to a re- 
duced concentration of ATD in the blood [3, 19]. In view of such situation, it is clear that safer and better therapies of TB patients are needed. The results of this randomized study in a representative population of TB patients indicates that the first line intravenous ATD have produced faster clearance of $M$. tuberculosis and healing destruction in the lungs at a significantly higher rate than in the control arm. This response rate, which occurred within such a short period of time, has rarely been seen in oral chemotherapy trials $[8,28]$.

It is well known that cough, pain in the chest, increased body temperature, fever, profuse night sweats, fatigue, dyspnea, and loss of weight and decreased appetite content are requisite parameters to gauge the severity of TB [26-28]. The return of these indices to normal is the symptom of disease control and a good correlation with sputum conversion have been found [5]. Caseous pneumonia, tuberculous meningitis, disseminated and miliary TB are independent risk factors associated with poor prognosis; intravenous ATD are known to reduce mortality among these TB patients [16, 21]. Intravenous ATD helps to reduce symptoms of intoxication in a higher proportion of patients, in other words, 61.2 versus $24.9 \%$ in control group - a ratio that matches sputum conversion rate. Consumption is a term historically synonymous with TB and represents poorly manageable wasting syndrome associated with malnutrition and chronic inflammation [29]. Finally, as judged by ALT and AST assays, intravenous ATD counteract drug-induced hepatotoxicity - an important factor that affects negatively compliance and success of TB chemotherapy.

What is the mechanism of intravenous ATD action? In each form of TB, immunopathological inflammation caused by the violation of microcirculation and trophic factors of lung tissue occurs, which may be complicated by its melting, secreting of caseating masses through the bronchi, and the formation of destructions (i.e., the process transition in the destructive form). This worsens the course of TB, resulting in the subsequent loss of a part or even the whole organ. All this complicates the penetration of oral ATD in the focus of tuberculous inflammation $[4,30]$. Intravenous chemotherapy increases the concentration of ATD in the blood in a short period of time, ensures a rapid access of these drugs to the focus of tuberculous inflammation and the use of solutions of intravenous ATD provides faster detoxication in patients with TB $[15,22]$. In addition, the results of studies during the past years have proved that the antimicrobial effect of ATD depends only on their maximum concentration in the blood, whereas the duration of contact with MBT is not significant [10, 25]. We demonstrated that intravenous administration of ATD allows creating a high level of bacteriostatic blood activity and maximum concentration in blood serum of patients as much as 2.5 times higher compared to oral use.

It should be mentioned that the treatment of patients with pulmonary TB with the use of i.v. chemotherapy accelerates normalization of TB clinical aspects and the progress of a specific process. No serious adverse events including severe allergic and toxic reactions to applied i.v. chemotherapy were observed. It was found that i.v. chemotherapy has been well tolerated and safe. Thanks to i.v. chemotherapy, the terms of abacillation and the frequency of destruction healing increased together with the frequency of achievement of complete clinical and radiological cure of patients with a decrease in the number of large residual changes after the treatment. In addition, due to the use of i.v. chemotherapy, more rapid penetration of drugs into specific focus of inflammation has been achieved, full bioavailability of drugs and a 100\% controllability of treatment has been observed.

This treatment effect will help to improve further patient's life after recovery of TB, prevent patient from disability due to TB and relapse of TB as well as development of drug resistance resistance of MTB [14], which in turn will reduce the costs of treatment of TB patients in the future.

Thus, the feasibility of i.v. chemotherapy for patients with pulmonary TB has been confirmed.

\section{Conclusions}

Thanks to i.v. chemotherapy, in patients with pulmonary TB, clinical aspects were eliminated faster, severe side effects of ATD have not been noticed, time of bacterial clearance and healing destruction is reduced, and the healing frequency of destructions is increased and the residual changes have been lessened.

\section{Acknowledgments}

We thank all volunteers who participated in the study. We acknowledge the wholehearted support of the clinicians, nurses, and lab personnel who contributed their efforts and made this study possible. Our gratitude is expressed to the experts in TB fields, of which there are too many to list, who kindly shared with us their opinions 
and suggestions prior to and after this study was completed.

This work was supported by the National Academy of Medical Sciences of Ukraine (No 0111U001173). The funder had no role in the study design, data collection and analysis, decision to publish, or preparation of the paper.

\section{Conflict of interest}

The authors declare no conflict of interest.

\section{References:}

1. World Health Organization, Global Tuberculosis Report 2017: WHO Report 2017. Geneva: WHO : 249 .

2. Dudnyk A, Butov D, Crudu V, et al. MDR-TB in Eastern Europe in the era of the TB elimination action framework. Int J Tuberc Lung Dis. 2017; 21(1): 2-3, doi: 10.5588/ijtld.16.0732, indexed in Pubmed: 28157456.

3. du Toit LC, Pillay V, Danckwerts MP. Tuberculosis chemotherapy: current drug delivery approaches. Respir Res. 2006; 7: 118, doi: 10.1186/1465-9921-7-118, indexed in Pubmed: 16984627.

4. Butov D, Zaitseva S, Butova T, et al. Efficacy and safety of quercetin and polyvinylpyrrolidone in treatment of patients with newly diagnosed destructive pulmonary tuberculosis in comparison with standard antimycobacterial therapy. Int J Mycobacteriol. 2016; 5(4): 446-453, doi: 10.1016/j.ijmyco.2016.06.012, indexed in Pubmed: 27931686.

5. Horsburgh CR. Tuberculosis. Eur Respir Rev. 2014; 23(131): 36-39, doi: 10.1183/09059180.00008213, indexed in Pubmed: 24591660.

6. Falzon D, Schünemann HJ, Harausz E, et al. World Health Organization treatment guidelines for drug-resistant tuberculosis, 2016 update. Eur Respir J. 2017; 49(3), doi: 10.1183/13993003.02308-2016, indexed in Pubmed: 28331043.

7. Mandal S, Chadha VK, Laxminarayan R, et al. Counting the lives saved by DOTS in India: a model-based approach. BMC Med. 2017; 15(1): 47, doi: 10.1186/s12916-017-0809-5, indexed in Pubmed: 28253922.

8. Sotgiu G, Sulis G, Matteelli A. Tuberculosis-a World Health Organization Perspective. Microbiol Spectr. 2017; 5(1), doi: 10.1128/microbiolspec.TNMI7-0036-2016, indexed in Pubmed: 28185618.

9. Chaudhry LA, Zamzami M, Aldin S, et al. Clinical consequences of non-compliance with directly observed therapy short course (DOTS): Story of a recurrent defaulter. Int J Mycobacteriol. 2012; 1(2): 99-103, doi: 10.1016/j.ijmyco.2012.05.003, indexed in Pubmed: 26787064.

10. Mitnick CD, McGee B, Peloquin CA. Tuberculosis pharmacotherapy: strategies to optimize patient care. Expert Opin Pharmacother. 2009; 10(3): 381-401, doi: 10.1517/14656560802694564 , indexed in Pubmed: 19191677.

11. Rusen ID, Aït-Khaled N, Alarcón E, et al. Cochrane systematic review of directly observed therapy for treating tuberculosis: good analysis of the wrong outcome. Int J Tuberc Lung Dis. 2017; 11(2): 120-121, doi: 10.1002/14651858.cd003343. pub2.

12. Kendall EA, Azman AS, Cobelens FG, et al. MDR-TB treatment as prevention: The projected population-level impact of expanded treatment for multidrug-resistant tuberculosis. PLoS One. 2017; 12(3): e0172748, doi: 10.1371/journal.pone.0172748, indexed in Pubmed: 28273116.
13. Tiberi S, Buchanan R, Caminero JA, et al. Presse Med. 2017; 46(2 Pt 2): e41-e51, doi: 10.1016/j.lpm.2017.01.016, indexed in Pubmed: 28256383.

14. Peloquin CA. Therapeutic drug monitoring in the treatment of tuberculosis. Drugs. 2002; 62(15): 2169-2183, indexed in Pubmed: 12381217.

15. Kimerling M, Phillips P, Patterson P, et al. Low Serum Antimycobacterial Drug Levels in Non-HIV-Infected Tuberculosis Patients. Chest. 1998; 113(5): 1178-1183, doi: 10.1378/ chest.113.5.1178.

16. Nahid P, Dorman SE, Alipanah N, et al. Executive summary: official American Thoracic Society/Centers for disease control and prevention/infectious diseases society of America Clinical Practice Guidelines: treatment of drug-susceptible tuberculosis. Clin Infect Dis. 2016; 63(7): 853-867, doi: 10.1093/cid/ ciw566, indexed in Pubmed: 27621353.

17. Gupta S, Cheung L, Pokkali S, et al. Suppressor Cell-Depleting Immunotherapy With Denileukin Diftitox is an Effective HostDirected Therapy for Tuberculosis. J Infect Dis. 2017; 215(12): 1883-1887, doi: 10.1093/infdis/jix208, indexed in Pubmed: 28863467.

18. Thiam S, LeFevre AM, Hane F, et al. Effectiveness of a strategy to improve adherence to tuberculosis treatment in a resource-poor setting: a cluster randomized controlled trial. JAMA. 2007; 297(4): 380-386, doi: 10.1001/jama.297.4.380, indexed in Pubmed: 17244834.

19. Peloquin CA, MacPhee AA, Berning SE. Malabsorption of antimycobacterial medications. N Engl J Med. 1993; 329(15): 1122-1123, doi: 10.1056/NEJM199310073291513, indexed in Pubmed: 8371737.

20. Nuermberger E, Grosset J. Pharmacokinetic and pharmacodynamic issues in the treatment of mycobacterial infections. Eur J Clin Microbiol Infect Dis. 2004; 23(4): 243-255, doi: 10.1007/ s10096-004-1109-5, indexed in Pubmed: 15024625.

21. Ruslami R, Ganiem A, Dian S, et al. Intensified regimen containing rifampicin and moxifloxacin for tuberculous meningitis: an open-label, randomised controlled phase 2 trial. The Lancet Infectious Diseases. 2013; 13(1): 27-35, doi: 10.1016/s14733099(12)70264-5.

22. Mehta J, Shantaveerapa H, Byrd R, et al. Utility of rifampin blood levels in the treatment and follow-up of active pulmonary tuberculosis in patients who were slow to respond to routine directly observed therapy. Chest. 2001; 120(5): 1520-1524, doi: 10.1378/chest.120.5.1520.

23. Drabkina PO, Bwanga F. Methods for determination of drug resistance of Mycobacterium tuberculosis and bacteriostatic activity of the blood of patients with tuberculosis: methodical letter. Kyiv: Zdorovya. 1969: 117-135, doi: 10.1007/978-0-38789370-9_8.

24. Lapach SN, Chubenko AV, Babich PN. Statistical methods in biomedical studies using excel. Kyiv: Morion; 2000. 2014: 320.

25. Antonenko P, Butov D, Kresyun V, et al. Association between effectiveness of tuberculosis treatment and cytochrome P-4502E1 polymorphism of the patients. Int J Mycobacteriol. 2017; 6(4): 396-400, doi: 10.4103/ijmy.ijmy_168_17, indexed in Pubmed: 29171455.

26. World Health Organization. Guidelines for treatment of tuberculosis fourth edition: World Health Organization. Geneva: WHO; 2010147.

27. World Health Organization. Treatment of tuberculosis: guidelines. Geneva: WHO; 2010. 160.

28. World Health Organization. TB CARE I. International Standards for Tuberculosis Care, Edition 3. Geneva: WHO; 2014214.

29. Schwenk A, Macallan DC. Tuberculosis, malnutrition and wasting. Curr Opin Clin Nutr Metab Care. 2000; 3(4): 285-291, indexed in Pubmed: 10929675.

30. Bloom BR. Tuberculosis: Pathogenesis, Protection, and Control. Washington: ASM Press. 1994. 